\title{
Acquisition of lightverbhood: Evidence from Cypriot Greek
}

Paraskevi Mavroudi, Evelina Leivada, Anna Epistithiou

Department of English Studies, University of Cyprus, Cyprus

https://doi.org/10.36505/ExLing-2010/03/0029/000149

\begin{abstract}
This experiment investigates the acquisition of (true) light verb constructions (in the sense of Kearns 1988/2002) as well as other constructions that involve a light verb in Cypriot Greek. Focusing on the acquisition of the light verb kamno 'do/make', this study aims to identify (i) whether light verb constructions are more frequent in Cypriot Greek than in Standard Modern Greek, (ii) what the age of acquisition is for true light verb constructions, and (iii) how sensitive to (light verb) priming children of different ages are in a picture-based elicitation task; in addition, this research tests

whether adults can be sensitive enough to priming so as to reproduce light verb constructions that are inexistent in Cypriot Greek.
\end{abstract}

Key words: acquisition, Cypriot Greek, lightverbhood, priming

\section{Lightverbhood: Theory and acquisition}

Kamno 'do/make' is a contentful verb (CV) that functions as 'light' in certain environments. In such light verb construction (LVC) environments, light verbs (LVs) combine with their complement (such as VP, NP, or AP) to form primary or complex predication. Primary predication arises from a phrase structure such as $\left[{ }_{v \mathrm{P}} \mathrm{DP}\left[v_{v^{\prime}} v \mathrm{XP}\right]\right]$, with DP the external argument (Hornstein et al. 2005: 108). The meaning of the LVC is the same as the equivalent $\mathrm{CV}$, and the main semantic content of the predication is provided not by the LV but by its complement (Kearns 1988/2002). With respect to its semantic status, we argue that kamno is a lexical verb that functions as light in such constructions by making no semantic contribution to the LVC, yet making an aspectual contribution, similar to what van Hout (1998) reports for 'aspectual' LVs in Dutch and Alexaki (2003) for kano, the Standard Modern Greek (SMG) variant of the Cypriot Greek (CG) kamno. Since we are unable to detect any semantic contribution of kamno to the overall meaning of the LVC, we suggest that it is semantically empty in the attested LVCs. The best way to account for the inability to detect its individual meaning in the meaning of the LVC is to suggest idiomaticity inside LVCs (Marantz 1998).

In CG, the only reference to lightverbhood in acquisition studies is an observation by Grohmann et al. (2010): Some of their test structures in the clitics-in-islands test they carried out were completed with LVCs, despite the fact that the experimenter primed children with a CV. In SMG, LVs were

ExLing 2010: Proceedings of 3rd Tutorial and Research Workshop on Experimental Linguistics, 25-27 August, Athens, Greece 
discussed in Alexaki (2003): In her longitudinal study, Christos until 2;0 used LVs to a limited extent (15\%-28\% of his total verb production). At the age of 2;4 this became $60 \%$ and after 2;5 LV-production decreased to $20 \%$.

\section{The present experiment}

We employed a picture-based elicitation task with 17 test sentences and 7 fillers. Test sentences were completed inside a because-declarative island, by producing an LVC and its internal argument, if one was available. Fillers required a simple picture description. All test sentences appear prima facie alike with respect to the LV and to the non-verbal part of the construction, which is always an NP; however, they can be divided into five types: (i) LVCs pass the Greek adaptation of Kearns' (1988/2002) tests for determining a true LVC (Type 1), (ii) LVCs that do not pass more than one of Kearns' tests (pronominalization and wh-movement, since passivization was not considered a reliable test in Cypriot Greek) (Type 2), (iii) the (true) LVC can be used in contexts in which the CV is not felicitous, whereas in Types 1 and 2 the two could be used interchangeably (Type 3), (iv) the CV can be used in contexts where the (true) LVC is not felicitous (Type 4), and (v) constructed LVCs that do not exist in adult speech, where the CV is stem-identical with the non-verbal part in 2 of the 3 structures (Type 5).

The subjects are divided into six age-groups ranging in age from $4 ; 0$ to 9;11, 20 in each age group: 10 receive as input the CV and 10 the corresponding LVC, to evaluate the significance of priming in such elicitation tasks. All children were monolingual in CG and were recruited randomly from 12 primary and pre-primary schools in the Nicosia district. The control group consisted of 12 adults (aged 20-54): 6 adults (mean 39;8) received LVC input, 6 adults (mean 31;5) received CV input. A typical example is the following (Type 1 item):

Experimenter: The girl is happy because the boy hugs her (= does/makes her hug). Why is the girl happy? The girl is happy because the boy...

(To koritsi en xarumeno jati to ayori kamni tu agaja. jati to koritsi en xarumeno? To koritsi en xarumeno jati to ayori...)

Child: ... does her hug. (... kamni tu agaja.)

\section{Findings}

First findings show that children extensively produce true LVCs with kamno already by the age of 4; even when primed with CVs, they employ LVCs in particular test sentences. All children are affected by LVC-priming to the extent that they reproduce Type 5-LVCs or construct their own inexistent ones or even produce, to a limited extent though, serial verb constructions of the form $[\mathrm{LV}-\mathrm{CV}]$ which are inexistent in adult speech.

In the LVC-version, across age groups, Type 1-items (true LVCs) are usually the ones less reproduced, whereas there is no observed pattern across 
age groups for a type that is more reproduced. Two children (aged 5;2 and $8 ; 0)$ produced four serial verb constructions (inexistent in adult speech) of the form [LV-CV], with kamno the LV and the corresponding contentful verb the CV. The production of our inexistent LVCs (Type 5 items) was surprisingly high across age groups:

Age group 4;0-4;11: $50.0 \%$ production

Age group 5;0-5;11: $\quad 73.3 \%$ production

Age group 6;0-6;11: $\quad 56.6 \%$ production

Age group 7;0-7;11: $\quad 96.6 \%$ production

Age group 8;0-8;11: $\quad 76.6 \%$ production

Adult control group: $27.7 \%$ production

These percentages show the effects of priming in this kind of elicitation task, since all participants were primed enough so as to produce structures that do not exist in their production otherwise. One of the primary aims of this study was to see whether LVCs are more frequently used in CG than in SMG. Calculating the LV use in findings from another elicitation task, the cliticsin-islands test (Leivada et al. 2010), this hypothesis seems to be correct. Different populations showed different LV use without LV-priming in this case: Both Hellenic Greek children and Greek Cypriot children received as input CVs. However, the latter group produced more LVs: $3.54 \%$ for Hellenic Greek and $6.45 \%$ for Greek Cypriot children, each percentage calculated for productions in a given participant's native variety.

Finally, the term employed so far to refer to verbs like kamno is 'light verb'. However the term 'General All-Purpose' (GAP) verbs has also been suggested in literature to refer to that type of verbs: "GAP verbs are defined as verbs that do not have a semantically specific meaning" (Goldberg et al. 2008: 43), referred to also as 'semantically flexible'. Stavrakaki (1998), in her discussion of the SMG kano, draws a distinction between the light kano and the idiomatic one, which she argues to be stored in the lexicon in the form of the idioms in which it appears. However, if we do not want to overload the conceptualization of our lexicon, there is no reason to assume two or three different $k a(m) n o$ stored there - one contentful, one idiomatic, one semantically flexible with light or general purpose, etc. Since none of the productions that our task elicited provides evidence for semantic flexibility in the use of kamno, we consider our test structures as involving aspectual light verbs: These are contentful verbs functioning as light in these environments by not making any semantic contribution to the meaning of the LVC.

\section{Acknowledgements}

This experiment was an idea that emerged from meetings of the Cyprus Acquisition Team (CAT), therefore we are grateful to all CAT members that 
participated for their insightful comments. Within the team, many thanks go to Maria Kambanaros who was the person both to answer all our queries about the connections of light verbs with Specific Language Impairment, but also to provide useful references and comments. Finally, this experiment would not have been carried out, had it not been for Kleanthes Grohmann and his constant help and support at every stage of this study.

\section{References}

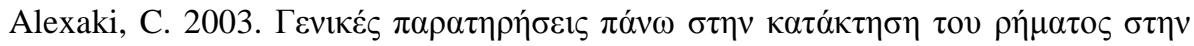

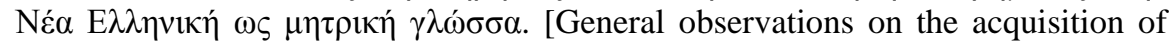
verbs in L1 Modern Greek]. In Catsimali, G., Kalokairinos, A., Anagnostopoulou, E. and Kappa, I. (eds.), Proceedings of the 6th International Conference on Greek Linguistics, Crete, Greece.

Grohmann, K.K., Theodorou, E., Pavlou, N., Leivada, E. 2010. Object clitics in typically-developing and language-impaired Cypriot Greek children. Poster presentation at the COST Action A33 final conference Let the Children Speak: Learning of Critical Language Skills across 25 Languages. Wellcome Collection, London, January 22-24.

Goldberg, H., Paradis, J., Crago, M. 2008. Lexical acquisition over time in minority first language children learning English as a second language. Applied Psycholinguistics 29, 41-65.

Hornstein, N., Nunes J., Grohmann, K.K. 2005. Understanding Minimalism. Cambridge: Cambridge University Press.

van Hout, A. 1998. Event Semantics of Verb Frame Alternations: A Case Study of Dutch and its Acquisition. New York/London: Garland.

Kearns, K. 1988/2002. Light verbs in English. Ms., Massachusetts Institute of Technology, Cambridge/University of Canterbury, Christchurch.

Leivada, E., Mavroudi, P., Epistithiou, A. 2010. (Meta)language in diglossic environments: Clitic placement by Hellenic Greek, Greek Cypriot and binational children. Poster presentation in Language Disorders in Greek 3, European University Cyprus, Nicosia (June 12-13).

Marantz, A. 1998. No escape from syntax: Don't try morphological analysis in the privacy of your own lexicon. In Dimitriadis, A. (ed.), Proceedings of the $27^{\text {th }}$ Annual Penn Linguistics Colloquium. Philadelphia, PA: Working Papers in Linguistics 4.

Stavrakaki, S. 1998. Kano: The case of a light verb in MG. In Lambropoulou, S. (ed.), Proceedings of the $12^{\text {th }}$ International Symposium of Theoretical and Applied Linguistics, vol. 1, 171-185. Thessaloniki, Greece. 